\title{
Filler selection for weldments in Type 316L stainless steel, for hot organic acid service
} C.P.M. Orsmond ${ }^{\mathrm{a}}$ and P.C. Pistorius ${ }^{\mathrm{b}}$

\author{
a. SecMet, PO Box 133, Seadoone 4126, South Africa; charl.orsmond@ megchem.co.za \\ b. Department of Materials Science and Engineering, Carnegie Mellon University, Pittsburgh \\ PA 15213, U.S.A.; pistorius@cmu.edu \\ (At the time this research was performed, both authors were with the Department of Materials \\ Science and Metallurgical Engineering, University of Pretoria, South Africa.)
}

\begin{abstract}
The weld metal corrodes much faster than the parent metal, if Type 316L welded with a matching filler is exposed to hot organic acids. Nine commercial filler metals were evaluated by preparing welded coupons, and exposing these to different plant environments (with different organic acid mixtures and temperatures) for several months. The filler metals were chosen to yield different solidification modes, and to vary chromium, molybdenum and nickel contents. Only filler metals which are much more highly alloyed than the parent metal gave lower corrosion rates than the parent metal. Partitioning during and after solidification, and the average alloy content, both affect weld bead corrosion.
\end{abstract}

Keywords: Austenitic stainless steel; welds; hot organic acid; solidification mode

\section{Introduction}

This paper deals with the corrosion of weldments, with Type 316L stainless steel parent metal, in hot organic acids. In-plant exposure tests were performed to evaluate different filler compositions. This section presents an overview of the process conditions and the observations which prompted the investigation.

\section{Plant conditions}

In the production unit where the tests were performed mixed organic acids are removed from reaction water by a reaction of the water with a solvent. The complex formed between organic acid and solvent enables effective density separation between the acids and water. The solventorganic acid complex is then heat stripped in a subsequent column (column A). This mixed acid mixture contains acetic acid $\left(\mathrm{CH}_{3} \mathrm{COOH}\right)$, propionic acid $\left(\mathrm{CH}_{3} \mathrm{CH}_{2} \mathrm{COOH}\right)$ and butyric acid $\left(\mathrm{CH}_{3} \mathrm{CH}_{2} \mathrm{CH}_{2} \mathrm{COOH}\right)$ and possibly small quantities of formic acid $(\mathrm{HCOOH})$. These acids are separated from one another in distillation columns based on differences in boiling point. In the first distillation column, column $\mathrm{B}$, the heavier acids $(\mathrm{C} 4$ and $\mathrm{C} 4+$, that is, containing four or more carbon atoms in the compound) are separated from the lighter ( $\mathrm{C} 3$ and $\mathrm{C} 3-)$ acids. The lighter acid mix is transported to column $\mathrm{C}$ where the propionic acid $\left(\mathrm{CH}_{3} \mathrm{CH}_{2} \mathrm{COOH}\right)$ is distilled out of the $\mathrm{C} 3$ and $\mathrm{C} 3-$ acid mixture. The lighter product ( $\mathrm{C} 2$ and $\mathrm{C} 2-)$ is then again pumped to column $\mathrm{D}$ where the final distillation is performed to produce high grade acetic acid (C2 acid). Other regions of the plant (identified by the letters $\mathrm{E}$ to $\mathrm{J}$ ) correspond to product streams, with various temperatures. Compositions and temperatures of the process streams are summarised in Tables 1 and 2 . 
Measured corrosion rates are given in Table 3. Type 316L austenitic stainless steel is regarded as a suitable alloy for the construction of equipment for the production of acetic and propionic acid. ${ }^{[1,2]}$ Published corrosion rates for type $316 \mathrm{~L}$ material in acetic acid distillation environments range between $<0.0025 \mathrm{~mm} / \mathrm{y}$ and $>1.25 \mathrm{~mm} / \mathrm{y}$ under conditions ranging between $10 \%$ acetic acid to concentrated acetic acid at temperatures ranging between $20^{\circ} \mathrm{C}$ to $212^{\circ} \mathrm{C}$. ${ }^{[1]}$ It is expected that the corrosiveness of the acid decreases as the chain length (and hence molar mass) of the organic acid increases. ${ }^{[3]}$ Of all the organic acids, formic acid is hence expected to be the most corrosive. ${ }^{[4]}$ It is further also expected that the corrosiveness of the organic acid will increase with temperature with the acids being the most corrosive near/at the relative boiling point of organic acid. Impurities like chloride are known to increase the corrosion rate significantly. ${ }^{[1,2,5]}$ It was also reported that contamination by elements such as $\mathrm{Cl}^{-}$ions can have a significant influence on the passivation behaviour of type $316 \mathrm{~L}$ austenitic stainless steel. ${ }^{[6]}$ The concentration of the organic acid may have a significant influence on the effect of such contaminants: steels in a medium containing $70 \%$ of acetic acid experienced a step change in the corrosion potential with $\mathrm{Cl}^{-}$additions, but this change in the corrosion potential was not seen in solutions containing $90 \%$ acetic acid. ${ }^{[6]}$

\section{Nature of corrosion attack}

Figure 1 shows a scanning electron micrograph of type 316L weld metal after exposure to the organic acid environment for a period of approximately 5 years at temperatures exceeding $125^{\circ} \mathrm{C}$; Figure 2 shows the appearance of base metal exposed under the same conditions. It is estimated that the corrosion rates of the filler material were an order of magnitude higher than that of the base material, based on the appearance of welds after exposure. As an example, Figure 3 shows a cross section of a typical weldment after exposure to the organic acid environment indicating how the filler material (weld cap) corroded preferentially, exposing the fusion line of the weld. Plant experience has shown that corrosion of welds was mostly interdendritic, as illustrated in Figure 1. Prolonged exposure of the welds resulted in preferential corrosion of the weld to such an extent that welds separated at the fusion line. Observation of welds during periodic inspections suggest that the corrosion rate increases after some initial attack: Welds which were inspected in one year appeared to be intact (though with a heavily etched surface), but were nearly completed corroded away at the next inspection. This may be related to corrosion attack along dendrites. Upon initial solidification of the weld metal, dendrite growth is largely perpendicular to the fusion line. As the weld pool moves away, the solidification direction further from the fusion line tends to follow the direction of welding, so that the cap solidifies with dendrite growth almost parallel to the welded plane. This change in dendrite direction may contribute to more rapid attack as corrosion proceeds along to the dendrites.

Poorer pitting corrosion resistance of stainless steel weldments (in chloride-containing environments) has been noted before, ${ }^{7,8}$ and ascribed to the partitioning of alloying elements (especially molybdenum and nitrogen) between austenite and ferrite, during and after solidification. Partitioning may similar affect the corrosion resistance in hot organic acids. 


\section{Experimental approach}

\section{Corrosion coupons and filler compositions}

To evaluate different filler materials, corrosion coupons were prepared using commercial type $316 \mathrm{~L}$ plate. Based on the available literature, an increase in $\mathrm{Mo}, \mathrm{Cr}$ and $\mathrm{Ni}$ may be expected to have beneficial effects on the corrosion resistance in organic acid environments.4.5 Commercial filler materials with higher alloying contents of these elements were therefore selected to be evaluated under production conditions. The commercial filler materials which were used are listed in Table 4. Field conditions would be repairs to fillet and butt welds and might consist of only a single bead repair in some cases. To simulate this, the plate was therefore grooved using a $5 \mathrm{~mm}$ cutting disk to generate a square groove approximately $5 \mathrm{~mm}$ wide by $5 \mathrm{~mm}$ deep. Single bead strips were welded into this on the plate with a shielded metal arc welding (SMAW) process; this preparation resulted in a slightly higher dilution than would be expected from a normal bead on plate weld. This was done to simulate the worst-case scenario where only single beads of weld overlay are deposited on corroded field welds. Spectrographic chemical analyses were performed on the weld metal to determine their chemical composition; these compositions are listed as "Actual" in Table 4; chromium and nickel equivalents given in Table 5 were calculated with the relationships of Rajashekar et al.: ${ }^{9}$

$$
\begin{aligned}
& \mathrm{Cr}_{\mathrm{eq}}=\% \mathrm{Cr}+\% \mathrm{Mo}+1.5 \% \mathrm{Si}+0.5 \% \mathrm{Nb} \ldots \ldots \ldots \ldots . .1 \\
& \mathrm{Ni}_{\mathrm{eq}}=\% \mathrm{Ni}+30 \% \mathrm{C}+0.5 \% \mathrm{Mn}
\end{aligned}
$$

The effect of the choice of filler metal on weld bead composition can be summarised as follows:

a. Composition comparable to the type 316L base material: type 316L filler (reference)

b. Slight increase in molybdenum: type 317L filler (Mo increased from $2.3 \%$ to 2.9\%)

c. Increase in chromium: type $309 \mathrm{MoL}$ filler ( $\mathrm{Cr}$ increased from $18.3 \%$ to $20.4 \%$ )

d. Increase in chromium and decrease in molybdenum: type 309L filler ( $\mathrm{Cr}$ increased from $18.3 \%$ to $21.1 \%$ and Mo decreased from $2.3 \%$ to $0.96 \%$ )

e. Increase in chromium and molybdenum, but a decrease in nickel: SAF 2205 and SAF 2507 fillers (Cr increased from $18.3 \%$ to $20.9 \%$ and $21.0 \%$ respectively, Mo increased from $2.3 \%$ to $2.9 \%$ and $3.2 \%$ respectively, Ni decreased from $11.7 \%$ to $9.6 \%$ and $10.3 \%$ respectively)

f. Highly alloyed filler materials, giving increases in chromium, molybdenum and nickel: type 625, 825 and 904L fillers (Cr increased from $18.3 \%$ to $19.0 \%, 25.1 \%$ and $19.3 \%$ respectively, Mo increased from $2.3 \%$ to $5.7 \%, 2.9 \%$ and $4.0 \%$ respectively, $\mathrm{Ni}$ increased from $11.7 \%$ to $39.8 \%, 26.8 \%$ and $20.6 \%$ respectively)

The significance of the ratio of chromium equivalent to nickel equivalent (as given in Table 5) is that this ratio correlates with the solidification mode: 9 Steels with $\mathrm{Cr}_{\mathrm{eq}}: \mathrm{Ni}_{\mathrm{eq}}<1.25$ solidify austenitically (mode "A"); as Table 5 shows, this is the case for the highly alloyed fillers. If $1.48<\mathrm{Cr}_{\text {eq }}: \mathrm{Ni}_{\mathrm{eq}}<1.95$ the steels follow the "FA" mode, with ferrite as primary phase, and austenite forming upon final solidification; this was the case for the $316 \mathrm{~L}, 317 \mathrm{~L}$, 309L and 309MoL fillers, and in this case the initial ferrite to form is expected to be significantly enriched in molybdenum relative to the average alloy composition. Steels with $\mathrm{Cr}_{\mathrm{eq}}: \mathrm{Ni}_{\mathrm{eq}}>1.95$ solidify as ferrite (mode "F"), with austenite precipitating in the solid state upon further cooling; this was 
the case for the duplex stainless steel fillers. For the samples used in this work, the microstructure of the weld metal was found to agree with the predicted solidification mode; ${ }^{10}$ examples are shown in Figure 4. Since the partitioning of elements is affected by solidification mode, the mode is also expected to affect corrosion behaviour; partitioning is expected to be significantly greater for weld metal solidifying in the FA mode than in metal following the A or F modes.8

Nitrogen in the weld metal is expected to affect the phase stability (and solidification mode), and may influence the corrosion rate. To test this, beads were welded with 309L filler, using argon containing controlled nitrogen additions as shielding gas, and subsequently exposed to the plant conditions.

\section{Exposure and evaluation of coupons}

Samples were installed in production columns and tested under production conditions. One coupon was used at each exposure location. Figure 5 indicates a typical coupon as inserted within a production column. Exposure times depended on production runs. The exposure times ranged between 120 to 214 days. All samples were pickled and passivated before exposure.

For these mediums, electrochemical tests could not be conducted since the mediums have a very low electrical conductivity, making electrochemical corrosion testing difficult. Due to the possible influence that elements commonly used to increase the conductivity of media, such as $\mathrm{Br}^{-}$and $\mathrm{Cl}^{-}$, could have on the corrosion reactions, addition of these as a background electrolyte was not possible. In addition, during some trial potentiodynamic measurements "masking" redox reactions were identified, with higher current densities than the actual corrosion reactions. These were presumed to originate from oxidation of the organic components in the electrolyte (since similar current densities were measured on platinum electrodes and stainless steel electrodes); this background current precluded electrochemical quantification of the rates of the corrosion reactions. Also, given that the attack is localised (and generally concentrated on specific phases in the weldments), the average electrochemical behaviour - even if this were measurable would have been of limited use in any case.

After exposure all samples were evaluated visually for any inconsistencies, pitting and galvanic corrosion. Polished cross sections of the exposed samples were prepared to evaluate differences in the corrosion rates of the filler material and the parent metal at the toe of the welds (see Figure 6). In Figure 6, the broken line indicates the surface of the coupon before corrosion. The coupons were welded in such a way that there was no undercutting at the weld toe. The undercutting (distance $c$ ) which developed during corrosion hence gives the difference between the corrosion of the weld bead (distance $a$ ) and that of the parent metal (distance $b$ ).

All exposed samples were also evaluated by scanning electron microscope (SEM). Attempts to analyse the phases in the weld beads by using the EDS (Energy-dispersive X-ray spectroscopy) facility of the SEM were not successful because the phases were often smaller than the interaction volume. For this reason, thin foils of selected samples were prepared for EDS analysis in a transmission electron microscope (TEM). Equilibrium partitioning of elements was predicted using Thermo-Calc. ${ }^{11}$ 


\section{Results and discussion}

Partitioning of elements in weld metal

For the weld metal which followed the ferrite-austenite solidification mode, the amount of ferrite remaining in the weld metal upon full solidification was predicted by using the WRC-92 diagram. $^{12}$ The amount of ferrite that remains in the weld metal after solidification and cooling to room temperature is affected both by the phase equilibria close to the melting point, and by the kinetics of ferrite-austenite phase transformation upon cooling. It was not attempted to model these kinetics, but an estimate of the partitioning of elements between ferrite and austenite was obtained from Thermo-Calc. The temperature employed in the equilibrium calculation was that which yielded the same ratio of ferrite to austenite as predicted by the WRC-92 diagram. The results are presented in Table 6. The results follow the expected effect, with chromium and molybdenum partitioning to ferrite, and nickel partitioning to austenite.

Measured element partitioning, for 309L filler (forming austenite upon final solidification), and for 2507 and 2205 fillers (forming austenite in the solid state after solidification) also confirmed this effect, as illustrated by Figure 7, which compares the predicted partitioning at $1200^{\circ} \mathrm{C}$ (Thermo-Calc) with the partitioning measured by TEM.

\section{Nature of corrosion attack}

In many cases, SEM investigation of corroded weld beads could be used to distinguish whether corrosion attack was more rapid on ferrite or austenite, for the metal which followed the FA solidification mode. Examples are shown in Figure 8, which is the same weld metals of which the predicted compositions are shown in Table 6. According to that table, the main difference between the different weld metals is that the 309L filler results in a significantly lower Mo content in both ferrite and austenite, and the 317L filler gives a significantly higher Mo content. Ferrite is expected to remain in the dendrite cores; the corrosion attack on the dendrite cores illustrates the importance of molybdenum and nickel, and their partitioning: in the higher-Mo weld beads, the corrosion rate of the ferrite is lower than of the austenite. In contrast, the ferrite corrodes slightly faster in the lower-Mo weld metal (likely because of the lower Ni content of ferrite, compared with austenite).

For the 2507 and 2205 fillers, formation of austenite by solid-state transformation gave a Widmanstätten structure; this was reflected in the fibrous appearance of the corroded weld bead (Figure 9). It was not possible to distinguish whether attack was faster on the ferrite or on the austenite. The highly alloyed fillers which gave fully austenitic solidification generally gave similar corrosion rates for dendrite cores and interdendritic regions (Figure 10).

Etch pitting, often resulting in the corroded surface having a tunnelled appearance, with the tunnels having square-shape cross-sections, were observed in several cases (Figure 11).

In all the instances where beads prepared with the type 825 and type 904L filler materials were exposed to the operating conditions large pits were observed in the weld metal (see Figure 12). 
All weld beads were examined for the features of which examples are shown in Figures 7 to 11, and the difference in corrosion rate between the weld bead and parent metal was evaluated using the procedure illustrated in Figure 6. The summarised results are presented in Table 7.

As shown by the table, a considerable concentration of alloying elements in the filler was required to ensure that the weld bead did not corrode at a higher rate than the base material. This was evident in the fact that in almost all the cases where the chemical composition of the filler material was comparable with the base material (i.e. type 316L, type 317L, type 309L and type $309 \mathrm{MoL}$ ) the weld bead corroded faster than the parent metal. It was only under condition $\mathrm{F}$ where the beads prepared with type 316 and type 317 fillers corroded at a similar rate to the parent metal, and conditions E, F and J where welds with type 309MoL filler corroded at a similar rate to the parent metal.

In the case of the duplex fillers, in some cases weld beads prepared with both filler materials corroded faster than the parent metal (i.e. conditions A, G and I). Under other conditions beads prepared with the type 2205 filler corroded faster than the parent metal, whereas beads prepared with the type 2507 filler corroded more slowly than the parent metal (i.e. conditions C, E, H and J). Under other conditions both beads prepared with both duplex fillers were more corrosion resistant than the parent metal (i.e. conditions A, D and F).

In all the cases beads prepared with the highly alloyed type 904L, type 825 and type 625 fillers were more resistant to the operating conditions than the type $316 \mathrm{~L}$ parent metal. In most of the cases beads prepared with the type 825 and type $904 \mathrm{~L}$ fillers showed areas of highly localised corrosion (pitting) within the beads (indicated by "PP" in Table 7).

In the cases where the filler corroded more slowly than the parent metal, no increased corrosion on the parent metal due to galvanic attack could be observed; since the conductivity of the organic acids is low, ${ }^{13}$ such galvanic attack would have caused localised deeper attack next to the weld bead, but this was not observed in any of the cases.

\section{Choice of filler}

Although all highly alloyed high-nickel alloy filler materials (904L, 825 and 625) produced beads which corroded at lower rates than the base material, the 625 filler material would be the preferred filler material thanks to the absence of any weld pitting (unlike beads prepared with the 825 and 904L fillers). It is not clear what the pitting mechanism is; Leontaritis and Horn observed pitting attack on austenitic stainless steels in hot acetic acid at chloride contents as low as 1 part per million. ${ }^{13}$

Beads prepared with the 825 filler material had $\mathrm{Cr}$ and $\mathrm{Ni}$ contents which were significantly higher than when using type 316L, 317L, 309MoL, 2205 and 2507 fillers, and with comparable molybdenum contents to beads prepared with the type 317L, type 2205 and 2507 fillers. The observation that beads prepared with type 825 filler material had significantly better corrosion resistance to the operating environment than beads prepared with these fillers suggests that a certain minimum concentration of chromium and nickel is required to improve the corrosion resistance of the filler material. However, available results do not allow any conclusion to be 
drawn on the individual and joint effects of molybdenum, chromium and nickel, beyond the general conclusion that the filler material needs to be quite highly alloyed to be resistant to these environments. In addition to the higher alloy content, the shift from the ferrite-austenite solidification mode to the fully austenitic mode is itself expected to improve corrosion resistance, through less partitioning. The results for nitrogen-alloyed welds support this suggestion, as briefly discussed below.

\section{Effect of nitrogen}

Figure 13 shows the nitrogen contents which could be obtained the 309L weld bead when using different nitrogen contents in the shielding gas during welding, together with the relative corrosion rate of weld metal and parent metal (as observed during subsequent plant exposure). Nitrogen contents of more than $0.2 \%$ could be obtained in this way; micrographs of the weld metal showed that the solidification mode was ferrite-austenite (FA) for the two beads with lower nitrogen contents, and austenitic (A) for the beads with the higher nitrogen contents (with no ferrite present in the weld metal in the latter two cases). In all cases the weld metal corroded faster than the parent metal, but the relative depth of corrosion was somewhat smaller for weld beads which did not contain delta ferrite. These results support the suggestion that the enhanced partitioning of alloying elements which is associated with the ferrite-austenite solidification mode increases the corrosion rate. While the fully austenitic solidification mode is associated

with a greater danger of solidification cracking, ${ }^{14}$ no cracks were observed in any of the weld beads.

\section{Conclusion}

Matching fillers corrode much faster than parent metal, for weldments in 316L stainless steel exposed to a range of hot organic acid environments. If a much more highly alloyed filler is used, the corrosion rate of the weld bead can be decreased to be lower than that of the parent metal. Factors which appear to influence corrosion of the weld metal include its chromium, molybdenum and nickel contents, and the solidification mode. Nitrogen has a small effect, apparently limited to its influence on the solidification mode.

\section{Acknowledgements}

We wish to thank MegChem Engineering and Drafting Services for sponsorship for this study, and Alison Tuling for assistance with TEM work.

\section{References}

1. D. Behrens (ed.): "Dechema corrosion handbook", volume 6, pp. 1-175; 1990, New York, VCH.

2. B.D. Craig and D.B. Anderson: "Handbook of corrosion data", pp. 88-110; 1997, Metals Park, OH, ASM International (1997).

3. A.J. Invernizzi, E. Sivieri and S.P. Trasatti: Materials Science and Engineering, 2008, $485,234-242$. 
4. C.M. Schillmoller: "Selection and use of stainless steels and nickel bearing alloys in organic acids", pp. 1-6; 1992, Nickel Development Institute, NiDI technical series No 10063.

5. P. Kangas, M. Newman: Anti-Corrosion Methods and Materials, 1998, 45, 233-242.

6. A. Turnbull, M. Ryan, A. Willetts and S. Zhou: Corrosion Science, 2003, 45 1051-1072

7. A. Garner: Materials Performance, 1982, 21(8), 9-14.

8. P.I. Marshall and T.G. Gooch: Corrosion, 1993, 49, 514-526.

9. K. Rajasekhar; C.S. Harendranath; R. Raman and S.D. Kulkarni: Materials

Characterization, 1997, 38, 53-65.

10. C.P.M. Orsmond: "The effect of filler metal on the corrosion resistance of stainless steel weldments in a hot organic acid environment", MEng dissertation, University of Pretoria, Pretoria, South Africa, 2010.

11. J.O. Andersson, T. Helander, L. Höglund, P.F. Shi and B. Sundman: Calphad, 2002, 26, 273-312.

12. W.R. Oates and A.M. Saitta: "AWS Welding handbook", eighth edition, volume 4, part 2 (1998), pp. 233-314.

13. L. Leontaritis and E.-M. Horn: Materials and Corrosion, 1988, 39, 313-321.

14. V. Shankar, T.P.S. Gill, S.L. Mannan and S. Sundaresan: Sadhana, 2003, 28, 359-382. 
Table 1: Typical chemical compositions (mass percentages) of the operating media during the tests, for plant areas A to $\mathbf{J}$

\begin{tabular}{|c||c|c||c|c|c|c|c||c|c||c||}
\cline { 2 - 11 } \multicolumn{1}{c|}{} & A & B & C & D & E & F & G & H & I & J \\
\hline \hline Acetic acid & $37-41$ & $<0.1$ & $37-41$ & $54-60$ & $<0.1$ & $54-60$ & 99.96 & 99.98 & 99.96 & 99.68 \\
\hline Propionic acid & $29-32$ & $2-4$ & $29-32$ & $41-45$ & 99.9 & $41-45$ & $<0.1$ & $<0.1$ & $<0.1$ & $<0.1$ \\
\hline Isobutanoic acid & $4-6$ & $13-16$ & $4-6$ & $<0.1$ & $<0.1$ & $<0.1$ & $<0.1$ & $<0.1$ & $<0.1$ & $<0.1$ \\
\hline Butanoic acid & $13-15$ & $40-44$ & $13-15$ & $<0.1$ & $<0.1$ & $<0.1$ & $<0.1$ & $<0.1$ & $<0.1$ & $<0.1$ \\
\hline $\begin{array}{c}\text { Isopentanoic } \\
\text { acid }\end{array}$ & $2-4$ & $8-11$ & $2-4$ & $<0.1$ & $<0.1$ & $<0.1$ & $<0.1$ & $<0.1$ & $<0.1$ & $<0.1$ \\
\hline Pentanoic acid & $3-5$ & $12-15$ & $3-5$ & $<0.1$ & $<0.1$ & $<0.1$ & $<0.1$ & $<0.1$ & $<0.1$ & $<0.1$ \\
\hline
\end{tabular}

Table 2: Typical operating temperatures $\left({ }^{\circ} \mathrm{C}\right)$ during the tests, for plant areas $\mathrm{A}$ to $\mathrm{J}$

\begin{tabular}{|c|c|c|c|c|c|c|c|c|c|}
\hline $\mathbf{A}$ & $\mathbf{B}$ & $\mathbf{C}$ & $\mathbf{D}$ & $\mathbf{E}$ & $\mathbf{F}$ & $\mathbf{G}$ & $\mathbf{H}$ & $\mathbf{I}$ & J \\
\hline $140-142$ & $178-180$ & $124-126$ & $118-120$ & $155-157$ & $153-155$ & $110-112$ & $129-131$ & $125-127$ & $85-87$ \\
\hline
\end{tabular}

Table 3: Corrosion rates [mm/y] of Type 316L plate, as determined with ultrasonic wall thickness measurements, for plant areas A to $\mathrm{J}$

\begin{tabular}{|c|c|c|c|c|c|c|c|c|c|}
\hline $\mathbf{A}$ & $\mathbf{B}$ & $\mathbf{C}$ & $\mathbf{D}$ & $\mathbf{E}$ & $\mathbf{F}$ & $\mathbf{G}$ & $\mathbf{H}$ & $\mathbf{I}$ & J \\
\hline \hline $0.29-0.42$ & $0.14-0.19$ & $0.10-0.17$ & $0.21-0.29$ & $0.09-0.17$ & $0.06-0.12$ & $0.11-0.21$ & $0.1-0.4$ & $0.2-0.8$ & $0.2-0.3$ \\
\hline
\end{tabular}

Table 4: Chromium, nickel and molybdenum contents (mass percentages) of filler materials, showing both nominal compositions and actual weld metal compositions.

\begin{tabular}{|c|c|c|c|c|c|c||}
\hline \multirow{2}{*}{ Filler material } & \multicolumn{2}{|c|}{ Cr } & \multicolumn{2}{c||}{ Ni } & \multicolumn{2}{c||}{ Mo } \\
\cline { 2 - 7 } & Nominal & Actual & Nominal & Actual & Nominal & Actual \\
\hline \hline Type 625 & $20.0-23.0$ & 19.0 & 55 min & 39.8 & $8.0-10.0$ & 5.7 \\
\hline Type 825 & $27.0-31.0$ & 25.1 & $35.0-40.0$ & 26.8 & $2.5-4.5$ & 2.9 \\
\hline Type 904L & $19.5-21.5$ & 19.3 & $24.0-26.0$ & 20.6 & $4.2-5.2$ & 4.0 \\
\hline Type 316L & $17.0-20.0$ & 18.3 & $11.0-14.0$ & 11.7 & $2.0-3.0$ & 2.3 \\
\hline Type 317L & $18.0-21.0$ & 18.0 & $12.0-14.0$ & 11.7 & $3.0-4.0$ & 2.9 \\
\hline Type 309L & $22.0-25.0$ & 21.1 & $12.0-14.0$ & 11.6 & 0.75 max & 0.96 \\
\hline Type 309MoL & $22.0-25.0$ & 20.4 & $12.0-14.0$ & 12.0 & $2.0-3.0$ & 2.2 \\
\hline SAF 2205 & $21.5-23.5$ & 20.9 & $8.5-10.5$ & 9.6 & $2.5-3.5$ & 2.9 \\
\hline SAF 2507 & $24.0-27.0$ & 23.0 & $6.5-8.5$ & 10.3 & $2.9-3.9$ & 3.2 \\
\hline
\end{tabular}

Table 5. Chemical composition (mass percentages) of as-deposited weld metal and parent metal, with chromium and nickel equivalents. The last column indicates the solidification mode.

\begin{tabular}{|c|c|c|c|c|c|c|c|c|c|c|}
\hline \multirow{2}{*}{ Filler material } & \multicolumn{6}{|c|}{ Elements } & \multirow{2}{*}{$\mathrm{Cr}_{\mathrm{eq}}$} & \multirow{2}{*}{$\mathbf{N i}_{\text {eq }}$} & \multirow{2}{*}{$\frac{\mathrm{Cr}_{\mathrm{eq}}}{\mathrm{Ni}_{\mathrm{eq}}}$} & \multirow{2}{*}{ Mode } \\
\hline & $\mathrm{Cr}$ & $\mathbf{N i}$ & Mo & $\mathrm{C}$ & $\mathbf{S i}$ & Mn & & & & \\
\hline Type 625 & 19.0 & 39.8 & 5.7 & 0.022 & 0.33 & 1.1 & 25.2 & 41.0 & 0.6 & A \\
\hline Type 825 & 25.1 & 26.8 & 2.9 & 0.036 & 0.40 & 1.7 & 28.7 & 28.7 & 1.0 & $\mathrm{~A}$ \\
\hline Type 904L & 19.3 & 20.6 & 4.0 & 0.025 & 0.31 & 2.5 & 23.8 & 22.6 & 1.1 & $\mathrm{~A}$ \\
\hline Type 316L & 18.3 & 11.7 & 2.3 & 0.031 & 0.66 & 0.8 & 21.5 & 13.0 & 1.7 & FA \\
\hline Type 317L & 18.0 & 11.7 & 2.9 & 0.025 & 0.59 & 0.8 & 21.8 & 12.9 & 1.7 & FA \\
\hline Type 309L & 21. & 11.6 & 0.96 & 0.034 & 0.63 & 0.9 & 23.0 & 13.1 & 1.8 & FA \\
\hline Type 309MoL & 20.4 & 12.0 & 2.2 & 0.021 & 0.62 & 0.8 & 23.6 & 13.0 & 1.8 & FA \\
\hline SAF 2205 & 20.9 & 9.6 & 2.9 & 0.027 & 0.55 & 1.1 & 24.6 & 11.0 & 2.2 & $\mathrm{~F}$ \\
\hline SAF 2507 & 23.0 & 10.3 & 3.2 & 0.042 & 0.48 & 0.9 & 26.9 & 12.0 & 2.2 & $\mathrm{~F}$ \\
\hline Parent metal & 18.2 & 11.9 & 2.0 & 0.015 & 0.44 & 1.5 & 20.8 & 13.1 & 1.6 & \\
\hline
\end{tabular}


Table 6: Summary of the ferrite-austenite balance as estimated phase percentages from the WRC 92 diagram, together with the predicted chemical compositions of ferrite and austenite at temperatures which yield this phase balance at equilibrium, using Thermo-Calc. Temperatures were $1200^{\circ} \mathrm{C}$ for $309 \mathrm{~L}$ and $309 \mathrm{MoL}$ and $1250^{\circ} \mathrm{C}$ for $316 \mathrm{~L}$ and $317 \mathrm{~L}$.

\begin{tabular}{|c||c|c|c|c||c||}
\hline \hline Type & Phase & \%phase & w\% Cr & w\% Mo & w\% Ni \\
\hline \hline \multirow{2}{*}{ 309L } & $\delta$ & 12 & 26.4 & 1.4 & 7.4 \\
\cline { 2 - 6 } & $\gamma$ & 88 & 20.4 & 0.89 & 12.2 \\
\hline \hline \multirow{2}{*}{ 309MoL } & $\delta$ & 16 & 25 & 3.22 & 7.6 \\
\cline { 2 - 6 } & $\gamma$ & 84 & 19.5 & 2.05 & 12.8 \\
\hline \hline \multirow{2}{*}{$316 \mathrm{~L}$} & $\delta$ & 7 & 22.2 & 3.5 & 7.6 \\
\cline { 2 - 6 } & $\gamma$ & 93 & 18 & 2.2 & 11.9 \\
\hline \hline \multirow{2}{*}{ 317L } & $\delta$ & 9 & 21.9 & 4.3 & 7.8 \\
\cline { 2 - 6 } & $\gamma$ & 91 & 17.7 & 2.7 & 12.2 \\
\hline
\end{tabular}


Table 7: Results of visual evaluation of the welds after exposure to the operating conditions.

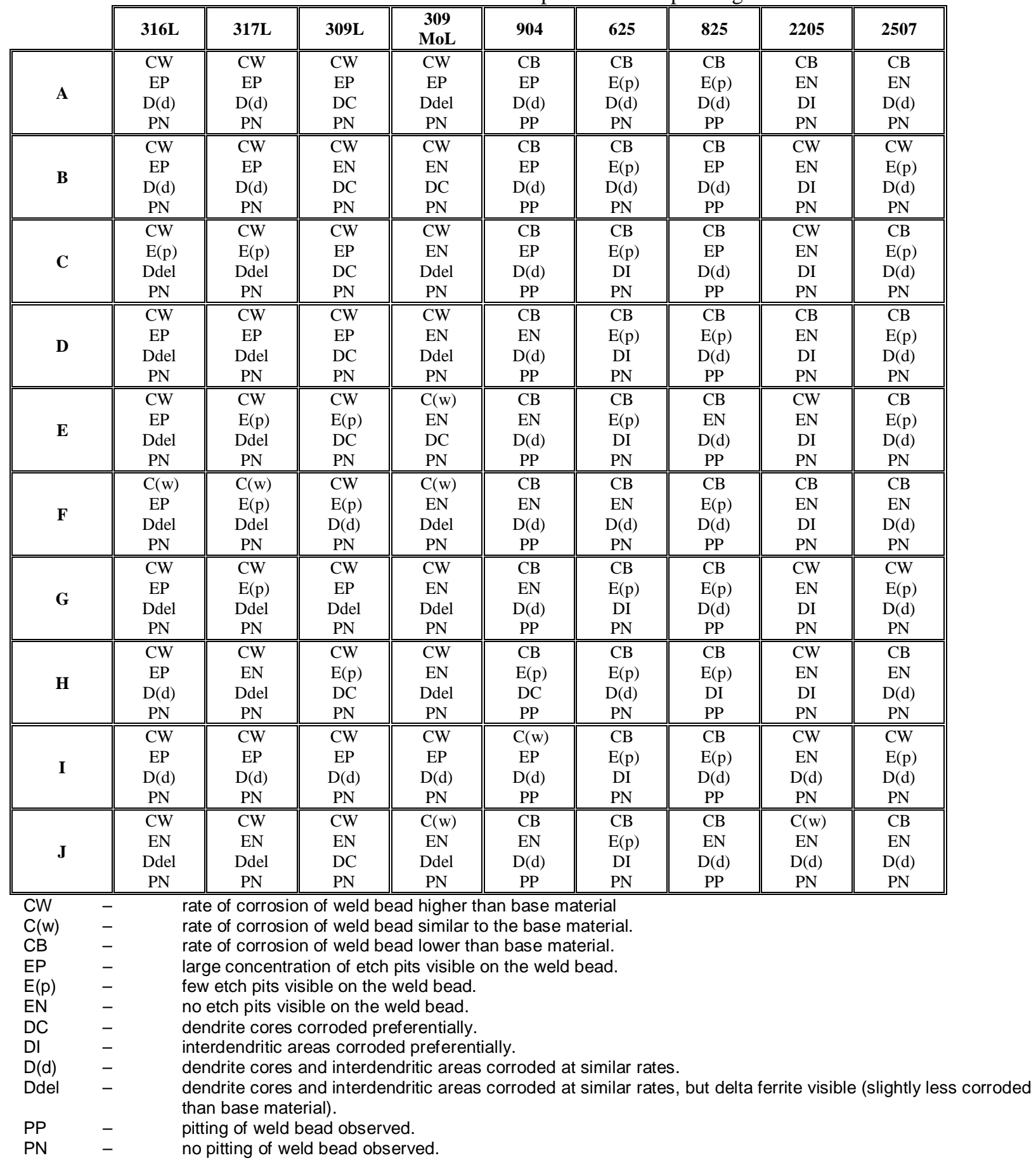




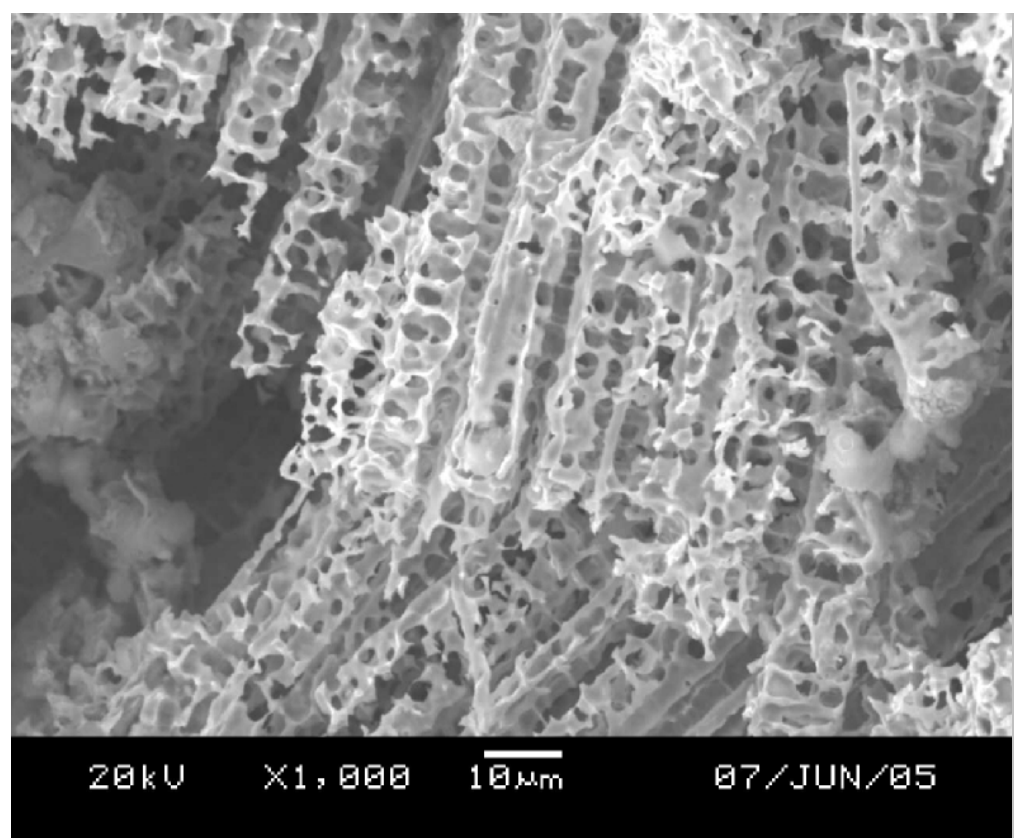

Figure 1: Scanning electron micrograph of a type 316L weld metal after exposure to hot acetic acid for five years.

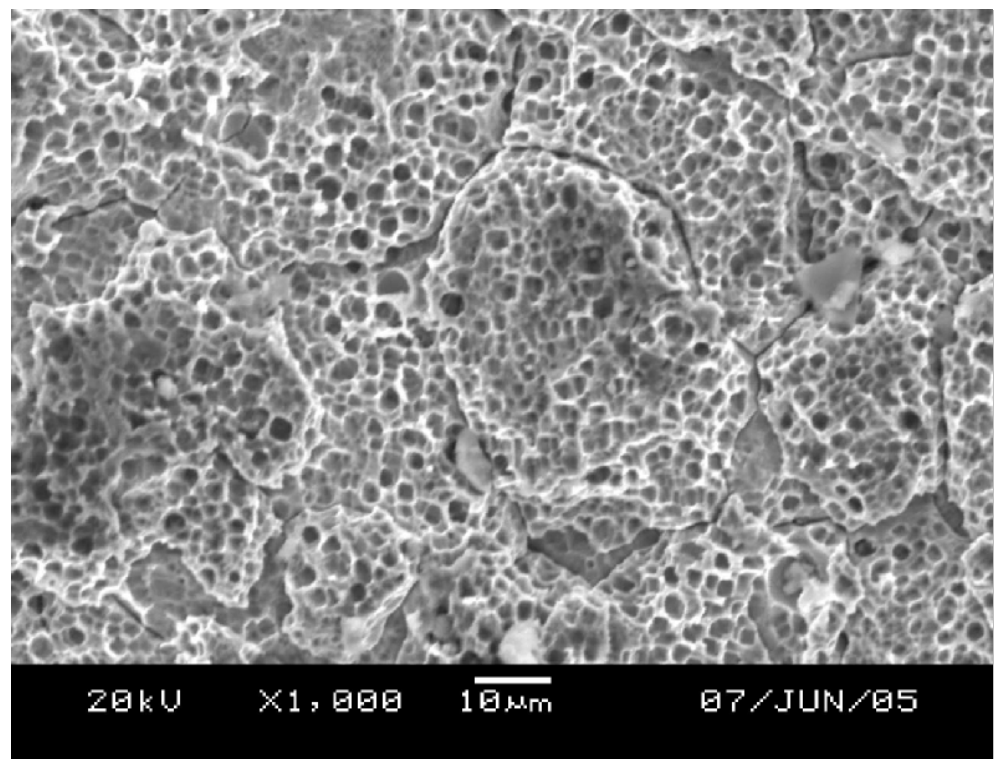

Figure 2: Scanning electron micrograph of a type 316L plate after exposure to hot acetic acid for five years. 


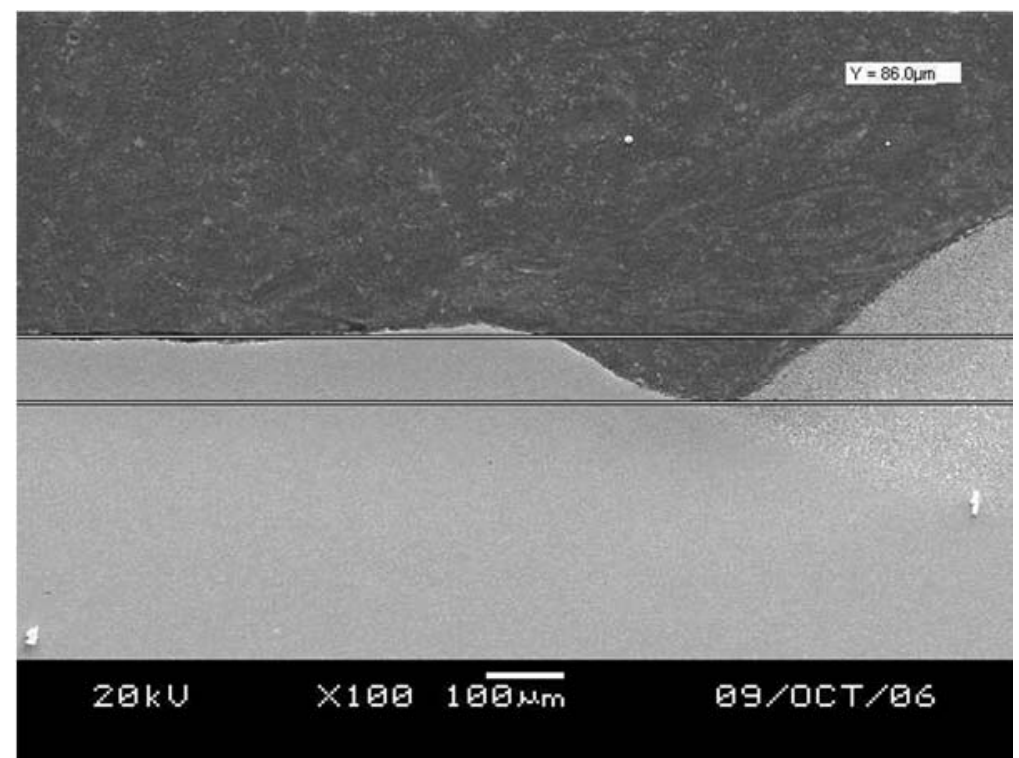

Figure 3: Scanning electron micrograph of a type 316L plate after exposure to hot acetic acid for five years.

a)

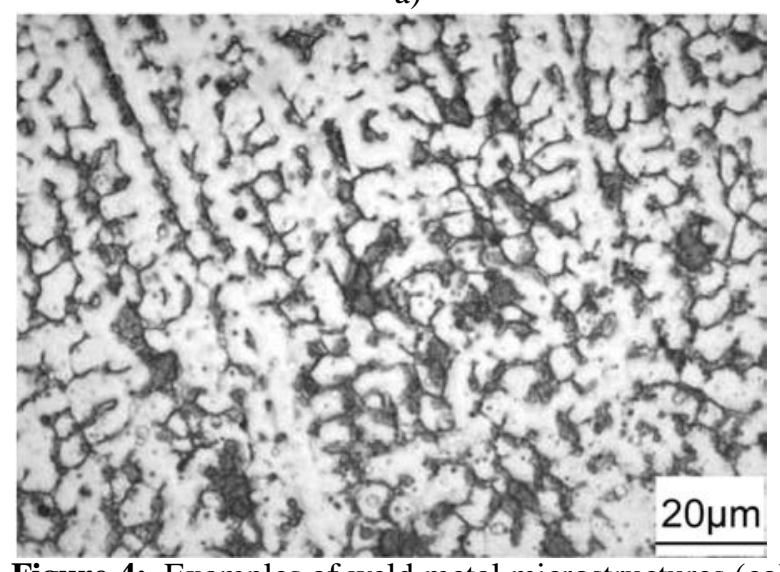

b)

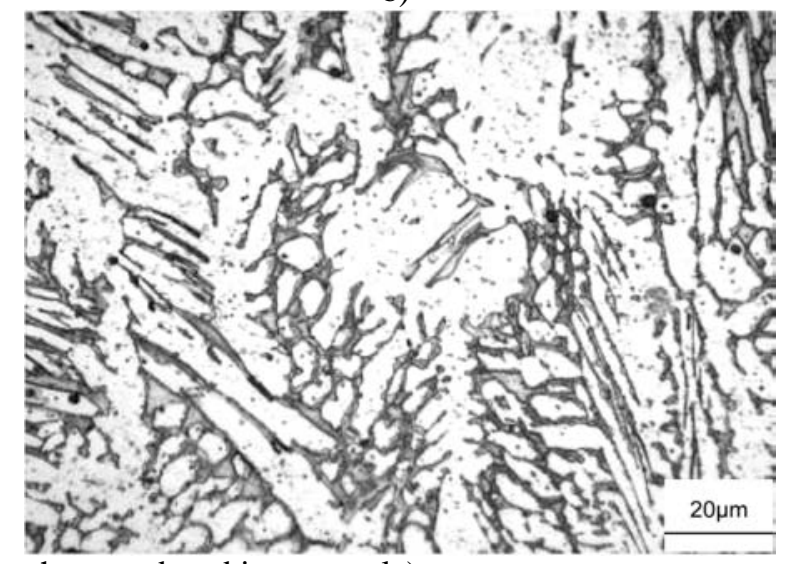

Figure 4: Examples of weld metal microstructures (colour etch, reproduced in greyscale).

a) $316 \mathrm{~L}$ filler (FA solidification mode); dark regions are dendrite cores (ferrite) with high $\mathrm{Cr} / \mathrm{Ni}$ ratio.

b) 2507 filler (F solidification mode); dark regions are ferrite remaining after solid-state formation of Widmanstätten austenite. 


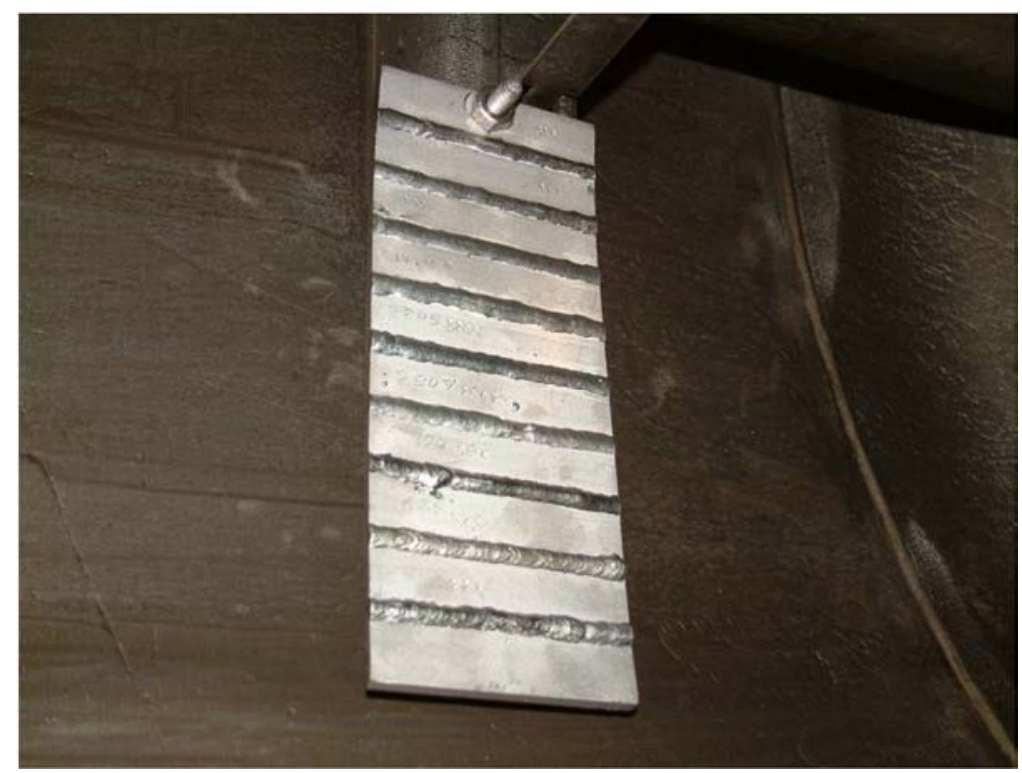

Figure 5: Photograph of a typical coupon as inserted within a production column; coupon is 100 mm wide and $300 \mathrm{~mm}$ long.

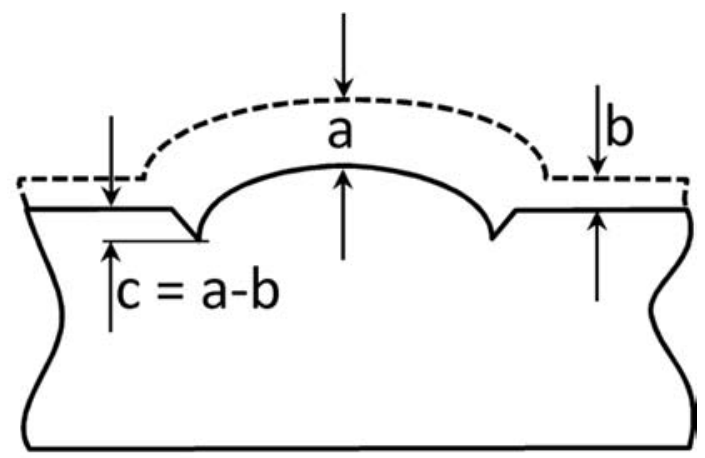

Figure 6: Schematic of the method used to determine the difference in weld bead and parent metal corrosion rates, by measuring the undercutting at the weld toe $(c)$ after corrosion. The broken line represents the position of the coupon surface before corrosion, and the solid line the surface after corrosion. 


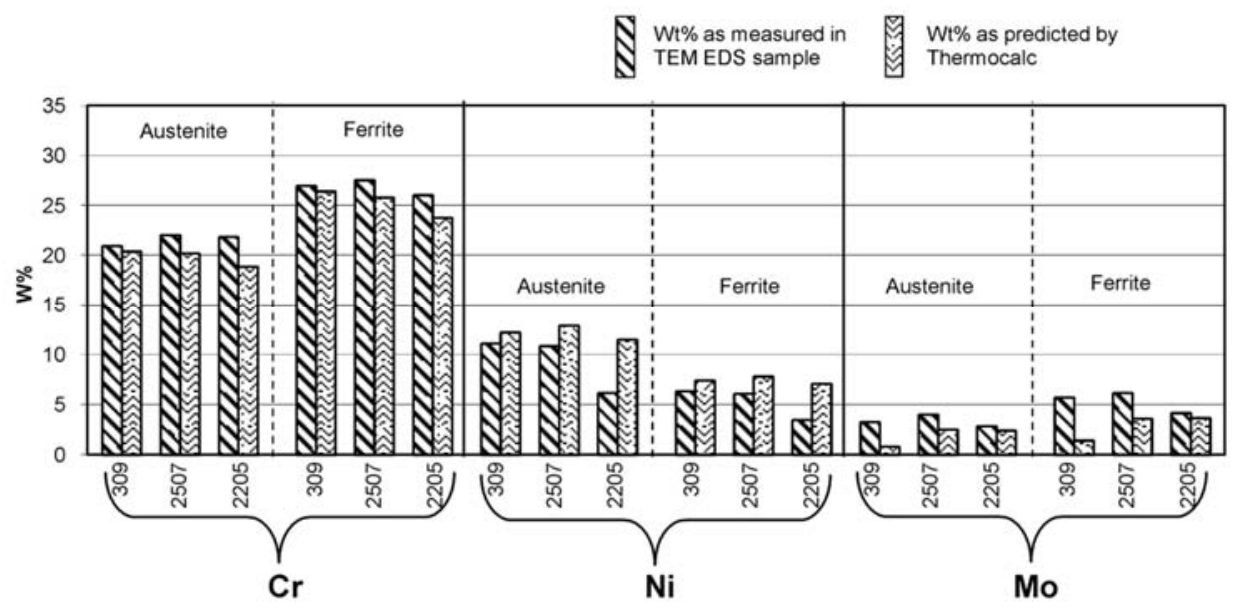

Figure 7: Comparison of measured compositions of ferrite and austenite (EDS analyses performed on TEM samples from weld beads) with the predicted chemical compositions (Thermo-Calc; $1200^{\circ} \mathrm{C}$ ).

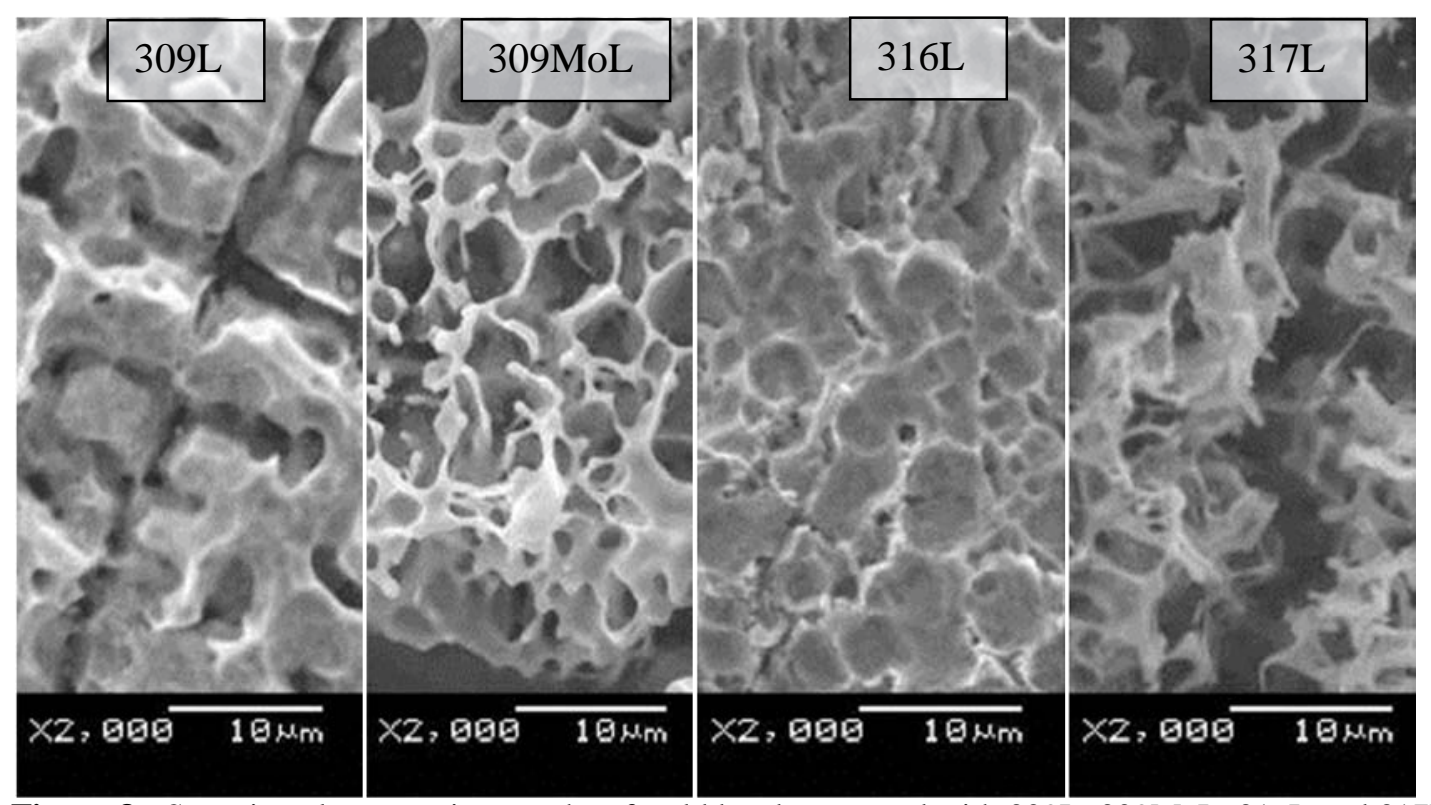

Figure 8: Scanning electron micrographs of weld beads prepared with 309L, 309MoL, 316L and 317L fillers, after 214 days of exposure to condition H. Fillers with higher Mo show less attack on the dendrite cores (ferrite), which is not the case for the lower-Mo filler (309L). 


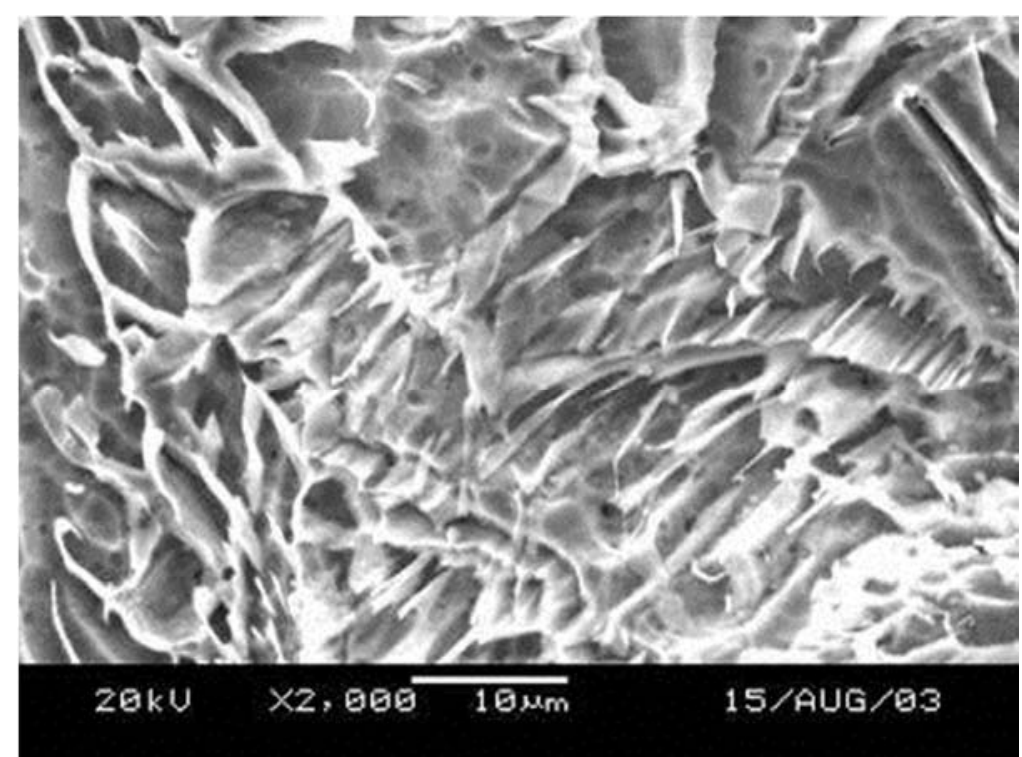

Figure 9: Typical appearance of corroded weld bead prepared with duplex stainless steel filler (2507 filler, condition A, 214 days).

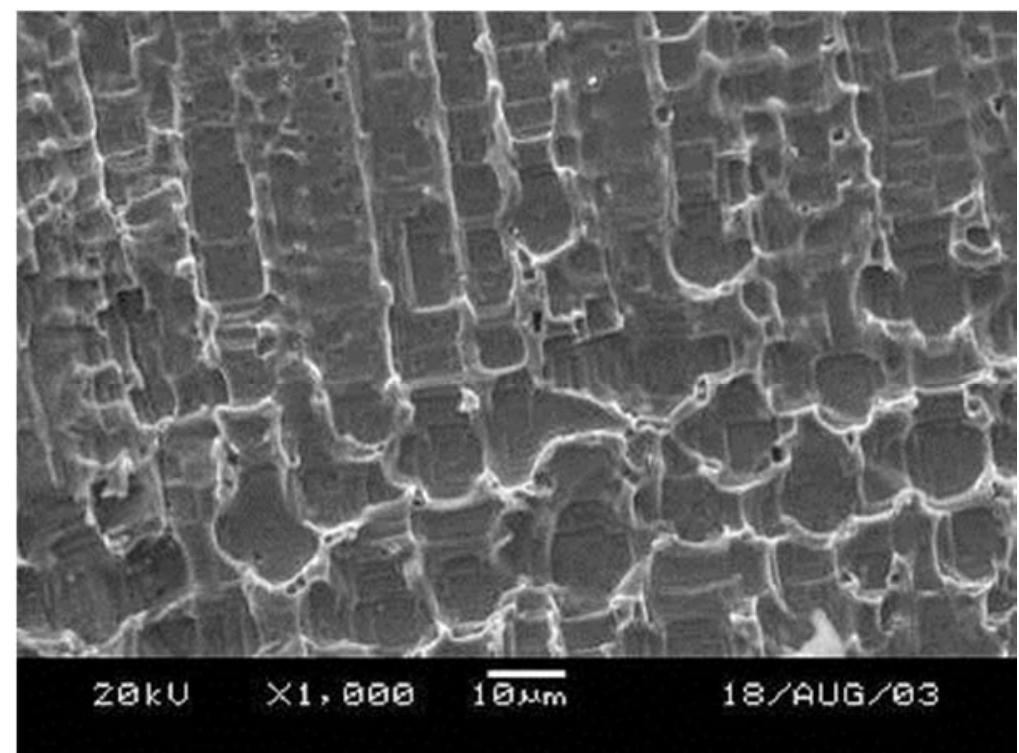

Figure 10: Shallower etching of weld bead which underwent fully austenitic solidification ( 904 filler material, condition B, 214 days). 


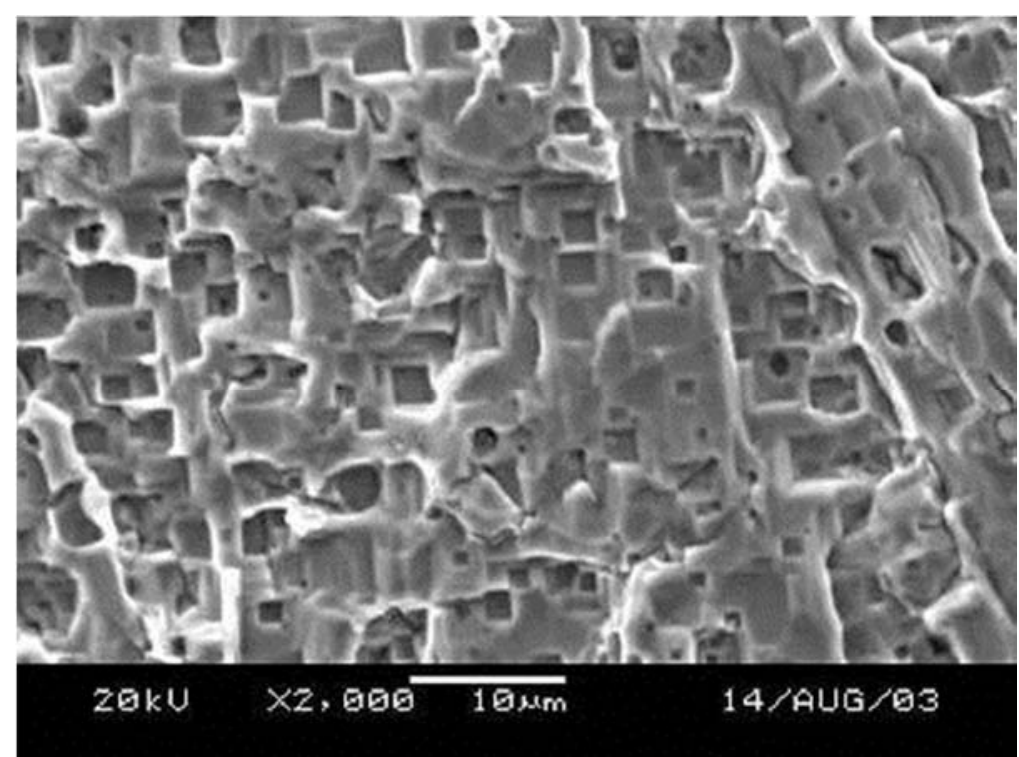

Figure 11: Example of etch pitting of weld bead (316L filler, condition D, 214 days)

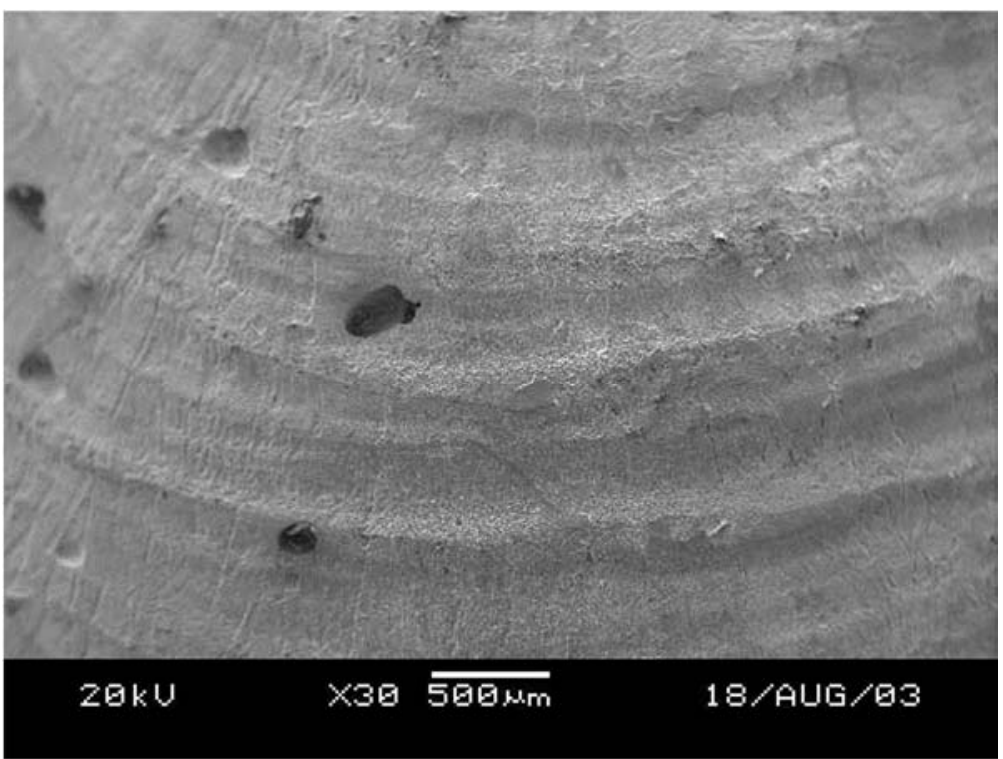

Figure 12: Typical pitting observed on the surfaces of beads prepared with type $904 \mathrm{~L}$ and 825 fillers. 


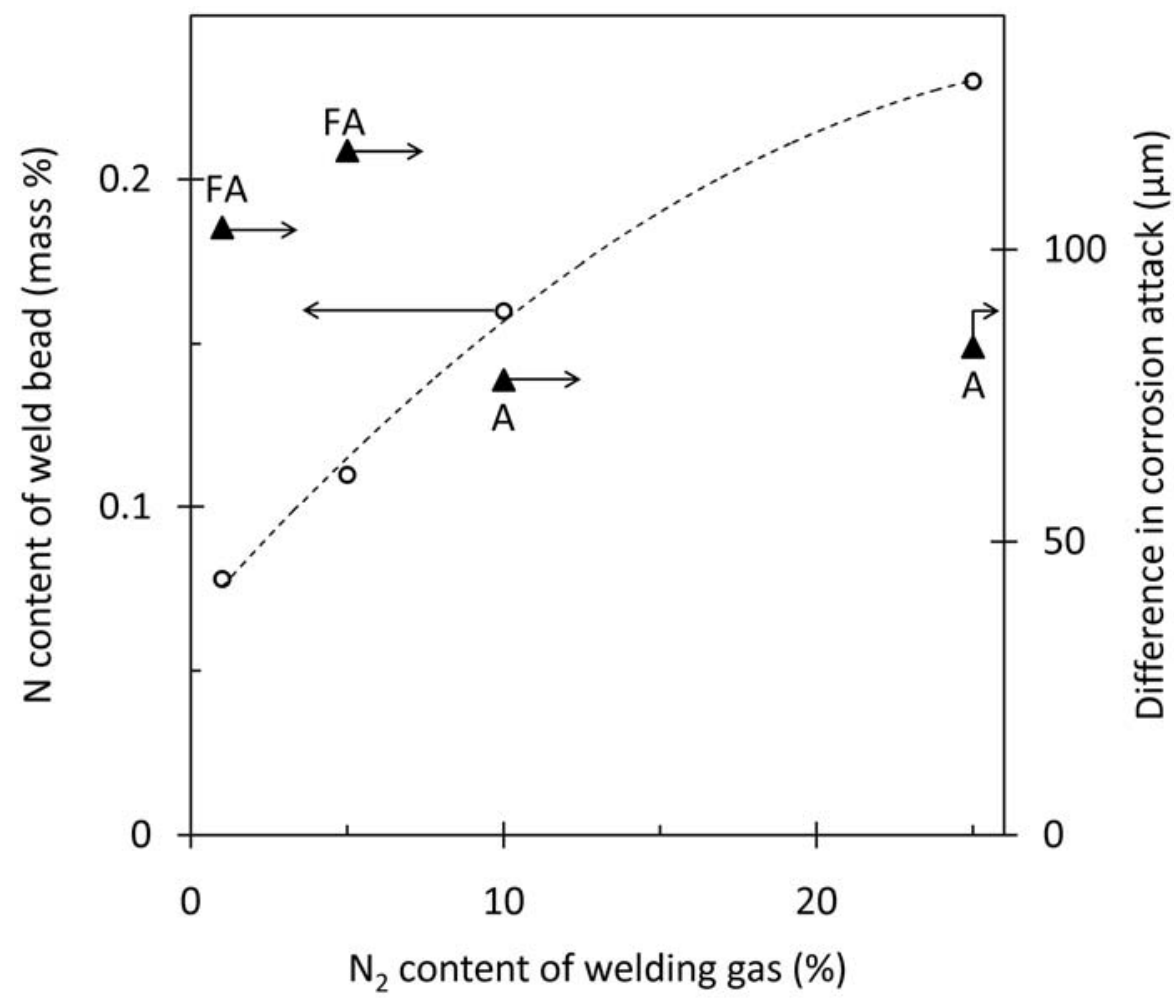

Figure 13: Nitrogen contents of 309L beads welded with different nitrogen contents in the shielding gas (circles and broken line), and the resulting difference in the depth of corrosion attack on the weld bead and parent metal (distance "c" in Figure 5; shown as triangles). The solidification mode (FA: ferrite-austenite, or A: austenitic) is indicated. Welding with lower nitrogen contents in the shielding gas yielded lower nitrogen contents in the weld bead (circles), resulting in the FA solidification mode and somewhat higher corrosion attack (triangles). 